\title{
MUDANÇAS, MOTIVOS E (RE)SIGNIFICAÇÕES: UM ESTUDO SOBRE A CONSTRUÇÃO DOS NOVOS OLHARES DE UMA INSTITUIÇÃO EDUCACIONAL ESPECIALIZADA FRENTE À INCLUSÃO ESCOLAR
}

\author{
CHANGES, REASONS AND (RE) MEANINGS: A STUDY ON THE \\ CONSTRUCTION OF NEW VIEWS OF A SPECIALIZED EDUCATIONAL \\ INSTITUTION AGAINST SCHOOL INCLUSION
}

DOI: http://dx.doi.org/10.5965/1984317815022019189

Francélio Ângelo de Oliveira
Instituto Federal de Educação, Ciência e Tecnologia do Ceará
angelooliveiraaee@gmail.com
Rita Vieira de Figueiredo
Universidade Federal do Ceará
aee.rita@gmail.com
Adriana Leite Limaverde Gomes
Universidade Federal do Ceará
adrianalimaverde@terra.com.br

\section{RESUMO}

Este artigo visa compreender as mudanças de concepções vivenciadas pela Associação de Pais e Amigos dos Excepcionais-APAE/Maranguape, no período de 2010 a 2013, com relação à inclusão escolar dos alunos que são público-alvo da educação especial. A fundamentação teórica se ancora em Vygotsky e Leontiev, que integram a chamada Psicologia histórico-cultural soviética ou socio-histórica. Trata-se de uma pesquisa de natureza qualitativa, cujo delineamento é o estudo de caso. Buscou-se compreender as singularidades existentes nos processos de ressignificações elaboradas pela instituição pesquisada. Os resultados mostraram que a construção do novo sentido que permeia e fundamenta os novos saberes e práticas da instituição, foram construídos através da relação interna de seus membros com outras formas de pensar a educação especial. Esse novo olhar aponta para o direito dos alunos da educação especial de se incluírem nas escolas comuns do ensino regular como principal recurso de mediação de sua aprendizagem.

Palavras-chave: Mudança; Ressignificações; Inclusão escolar.

\section{ABSTRACT}

This article aims to understand the changes in conceptions experienced by the Association of Parents and Friends of the Exceptional-APAE / Maranguape, in the period from 2010 to 2013, regarding the school inclusion of students who are the target audience of special education. The theoretical foundation is anchored in Vygotsky and Leontiev, that integrate the so-called historical-cultural Psychology Soviet or socio-historical. It is a qualitative research whose design is the case study. It was sought to understand the singularities existing in the processes of resignification elaborated by the researched institution. The results showed that the construction of the new meaning that permeates and underlies the new knowledge and practices of the institution, were built through the internal relationship of its members with other ways of thinking 
special education. This new view points to the right of special education students to be included in regular schools as the main resource for mediation of their learning.

Keywords: Change; Resignations; School inclusion.

\section{INTRODUÇÃO}

Neste artigo abordaremos a mudança vivenciada pela Associação de Pais e Amigos dos Excepcionais-APAE/Maranguape, no período de 2010 a 2013. O recorte temporal precede o ideário da instituição que, desde o ano de 2002, com o advento do II Fórum de Educação Especial, defendeu a proposta de uma educação inclusiva como direito de todos, aderindo à escola comum inclusiva como frente de luta. Nesse sentido, as novas concepções dessa instituição, que nortearam a ruptura de práticas segregadoras, acenaram para a implantação de um centro de atendimento educacional especializado.

Destacamos, portanto, o ano de 2010, como marco inicial da pesquisa, por ser o período em que foi criado o centro de atendimento educacional especializado. Entretanto, apenas em 2011, a APAE/Maranguape abdicou de funcionar como escola substitutiva, e passou a atrelar a oferta de seus serviços, à matrícula dos alunos público alvo da educação especial na rede regular de ensino.

Discutiremos a mudança no interior da instituição sob dois aspectos, são eles: as razões que motivaram a mudança através do processo de construção dos novos significados, e, os sentidos que viabilizaram tal mudança. Acreditamos que a disponibilidade à mudança ocorre no seio de uma organização, no momento em que se dá a articulação entre os interesses subjetivos em seu âmbito individual e as motivações coletivas. Essas últimas, ao se instalarem no imaginário do grupo, constroem os novos significados e sentidos, que nortearão as novas práticas.

No atual cenário da inclusão escolar, diante dos embates, resistências e acirramentos instala-se um mal estar frente à compreensão de algumas instituições, assim como entre outros grupos políticos, sobre o lugar a ser ocupado pelas escolas especiais. Frente a esses vários entraves, são vários os questionamos: Qual o destino 
das escolas especiais? Qual o seu novo papel frente à proposta da inclusão? Seria o fim das escolas especiais?

Diante dessa realidade, no presente texto, nos debruçaremos, especificamente, sobre as mudanças de uma instituição especializada, que passou de uma escola especial substitutiva ao ensino regular, para uma instituição especializada na oferta do atendimento educacional especializado complementar e/ou suplementar a escolarização. Essa mudança passou a provocar junto ao seu município a construção de um sistema educacional inclusivo, sendo uma das pioneiras do Estado do Ceará, e também no Brasil, a se credenciar como centro de atendimento educacional especializado.

Nesse contexto, indagamos: o que ocorreu no interior da instituição que a motivou a mudar? Que mudanças conceituais aconteceram, de modo a fundamentar a busca por seu redimensionamento? Como se deu o processo de apropriação de novos significados e sentidos, que a levou a buscar tal mudança? Quais os motivos da mudança? Norteados por essas indagações, objetivamos investigar os motivos que levaram a APAE/Maranguape promover mudanças na oferta de seus serviços, considerando a construção de novos significados e sentidos.

A fundamentação teórica se ancora em Vygotsky e Leontiev, que integram a chamada Psicologia histórico-cultural soviética ou socio-histórica. Para esses autores, o desenvolvimento humano ocorre a partir da imersão do homem nos contextos histórico e cultural. Nesse sentido, eles compreendem o homem como síntese de múltiplas determinações. Para Leontiev (1978), a atividade medeia à ação humana, inclusive impactando sua estrutura orgânica. Desse modo, significado e sentido são produzidos por um sujeito situado em um processo histórico, e, em uma determinada cultura. (VYGOTSY, 2000). 


\section{PERCORRENDO A LITERATURA}

\subsection{O surgimento das instituições especializadas: uma reflexão sobre sentidos e práticas}

No Brasil-colônia, apesar de algumas iniciativas isoladas de escolarização de pessoas com deficiência, apenas em 1854, a partir do incentivo direto do Governo Central e o apoio de outros atores, dar-se-ia origem a uma ação mais efetiva para a criação do Imperial Instituto dos Meninos Cegos. De acordo com Guerreiro (2007), o cego Álvares de Azevedo se destacou, nessa luta, ao se dedicar a causa dos cegos brasileiros, após retornar da França em 1851, onde realizou seus estudos no Instituto dos Jovens Cegos de Paris. Após traduzir e publicar o livro de J. Dondet - A História do Instituto dos Meninos Cegos de Paris - ele ganhou o apoio do médico do Imperador, José Francisco Sigaud, que era pai de uma menina cega, e, do conselheiro Luiz Pereira do Couto Ferraz, que encaminhou o projeto criando, em 1854, a referida instituição.

No ano de 1856, Ernesto Hüet e seu irmão fundaram o Instituto dos SurdosMudos, com recursos adquiridos junto ao Governo de D. Pedro II. Posteriormente, essa instituição passou a ser chamada de Instituto Nacional de Educação dos Surdos.

Nos relatos de Jannuzzi (1992), o alcance dessas duas instituições (Imperial Instituto dos Meninos Cegos e Imperial Instituto dos Surdos-Mudos) no tocante ao atendimento de seu público alvo, era extremamente limitado. No ano de 1874 eram atendidos, respectivamente, nessas instituições, 35 alunos cegos e 17 surdos, de uma população de 15.848 cegos e 11.595 surdos, em 1872. O surgimento desses institutos especializados contribuiu com a discussão, que possibilitou o Imperador realizar, em 1883, o I Congresso de Instrução Pública, embora a atenção escolar a esse segmento da população ainda fosse precária. Dentre os temas abordados no congresso, enumeramos: sugestões para o currículo e formação de professores de surdos e cegos. Apesar da iniciativa, a escolarização das pessoas com deficiência ainda não 
compunha o quadro de prioridades do governo, e ele se esquivou de realizar gastos decorrentes desse processo, ficando sob a responsabilidade das províncias.

Segundo (MAGALHÃES, 1913; RIBEIRO, 1943; JANNUZZI, 1992), no final do Império, se a educação das camadas populares era esquecida, muito mais a de pessoas com deficiência intelectual. Desse modo, apenas duas instituições realizavam atendimento médico e pedagógico dessa parcela da população, a saber: um espaço localizado nas dependências do Hospital Juliano Moreira em Salvador (BA), que data de 1874, e, o outro, conhecido como Escola México, criada em 1887, localizada no Rio de Janeiro. Essa última estendia também seu atendimento às pessoas com deficiência física e visual.

No Brasil, constatamos nos estudos de Magalhães (1913) e Jannuzzi (1992) a participação determinante dos médicos para o processo de atendimento $\mathrm{e}$ escolarização das pessoas com deficiência intelectual. Partiu desses profissionais, a iniciativa de criar espaços escolares ligados aos hospitais psiquiátricos, por compreenderem a importância da pedagogia no atendimento às crianças, na época classificadas com grave comprometimento mental e social. Inicialmente, essas crianças eram mantidas nesses espaços de isolamento social, juntamente com adultos que apresentavam quadro clínico de "loucura".

Em 1905, a criação, pelos médicos Juliano Moreira e Fernando Figueira, do Pavilhão Bourneville, anexo ao Hospício da Praia Vermelha, na cidade do Rio de Janeiro, se deu a partir de denúncias de uma comissão instaurada para investigar o estado em que se encontravam os então "alienados" presentes no Hospício Nacional e na Colônia da llha do Governador.

De acordo com os relatos de Magalhães (1913) a comissão era composta pelos médicos Carlos Fernando Eira, Antonio Teixeira; e Egidio de Salles Guerra e do farmacêutico M. F. da Silva Araújo. Era grande o desapontamento desses profissionais ao visualizarem crianças passeando em meio aos corredores do hospício, ao lado de adultos com graves quadros de transtorno, alguns se expondo a nudez. 
Após a constatação, a comissão se reportou ao ministro da Justiça relatando a preocupante situação, em que crianças dividiam o mesmo espaço com adultos, sujeitas a presenciarem até mesmo cenas obscenas. Desse modo, indicou-se a construção de um pavilhão infantil, anexo ao hospício, onde seriam realizadas as intervenções médicas e educativas como parte do tratamento. Acreditando-se que, desse modo, haveria condições adequadas para que elas apresentassem melhoras. Com a iniciativa dar-se-ia origem as orientações pedagógicas, concomitantemente, ao atendimento clínico. (JANNUZZI, 1992)

De acordo com a pesquisa de Müller (1998), o tratamento oferecido a essas crianças se dava, inicialmente, com a organização do espaço, em seguida, eram definidas as intervenções terapêuticas. As crianças eram agrupadas mediante a uma ferrenha classificação, que começava pelo sexo, em seguida eram separadas em três grupos, segundo o quadro de deficiência ao qual eram caracterizadas:

O $1^{\circ}$ é composto por crianças na época denominadas de idiotas, cretinas, epiléticas ou não, mas "inválidas"; o $2^{\circ}$ por crianças idiotas, cretinas ou não, mas "válidas" e o $3^{\circ}$ por crianças apropriadas, válidas, imbecis, retardadas, instáveis, perversas, epiléticas e histéricas ou não. (MÜLLER, 1998, p.85)

O elenco de atividades oferecidas no atendimento às crianças foi formulado sob uma ótica classificatória e estigmatizante. Ou seja, a oferta escolar se organizava de modo a segregar todos aqueles que se desviavam do padrão normalizador, e, se dividia, de acordo com escalas, previamente, demarcadas, a partir do que se estipulava como normal.

[...] Para o "idiota válido" a pequena escola, para o "inválido", o tratamento reabilitador e higiênico, para os adolescentes, as oficinas, para os demais a grande escola. Essa forma de organização do espaço e do tempo das crianças, garantiam o processo disciplinar, onde a criança era todo o tempo vigiada e controlada, numa junção perfeita entre o regime hospitalar classificatório, compondo um quadro geral e perfeitamente e perfeitamente visível e sistematizado de uniformidades. (MÜLLER, 1998, p. 85)

O censo de vigilância e controle estava presente no olhar e nas práticas do Estado, quanto ao tratamento das crianças com algum tipo de "desvio" em relação ao 
padrão "normal". O diagnóstico era realizado pelos médicos peritos da polícia, que após avaliação, encaminhava às crianças ao internamento. No formulário de encaminhamento estava disposto que a delegacia deveria ser informada nos casos de alta ou eventual saída da criança. Isto demonstra a relação estabelecida entre deficiência e periculosidade, tendo como base para as internações as prescritivas policiais, justificando essas práticas através de supostos riscos morais e a ordem pública. (MÜLLER, 1998)

O atendimento institucional estava ligado a uma espécie de correção ou reparo moral, no qual a pessoa era isolada e tratada mediante técnicas terapêuticas e pedagógicas. Esse atendimento objetivava que essas crianças "anormais" se tornassem o mais lucrativa possível para a sociedade de consumo, se tornando responsáveis pela sua própria manutenção. Cabia ao médico, mediante sua classificação, apontar em quais crianças se investiria e quais deveriam ser abandonadas. Assim se travava o destino desses meninos. (MÜLLER, 1998)

Todas as manifestações "desviantes" são ameaçadoras da ordem estabelecida. Portanto, a anormalidade era tida como um risco moral e à segurança, por isso a necessidade de disciplinar o indivíduo, para que ele atingisse níveis mais elevados de normalização. Como estratégia, estruturou-se um método médico-pedagógico a ser desenvolvido nas instituições hospitalares, numa perspectiva educativa para quem:

A internação era parte do tratamento, e tinha como objetivo a correção, o ajustamento social e a adequação às normas sociais e onde também a criança poderia melhorar espontaneamente, evitando futuros prejuízos econômicos e sociais ao Estado. (MÜLLER, 1998, p. 92)

De acordo com Muller (1998), inicialmente, os objetivos perseguidos se voltavam para a apropriação de uma socialização adequada e para o desenvolvimento das atividades da vida diária (AVD's). Em seguida, era realizado o que se chamava de ensino dos sentidos, que consistia na estimulação dos sentidos (estimulação visual, auditiva, gustativa, sinestésica) numa perspectiva funcional. Posteriormente, 
trabalhava-se o condicionamento de uma rotina, com o intuito de minimizar os desvios de conduta.

Estudos realizados por Müller (2005) mostram que o Presidente da República Getúlio Vargas criou a Inspetoria Geral do Ensino Emendativo, por meio do Decreto 24.794, aos 14 de julho de 1934. Sua intenção era de agrupar as instituições, que ora atendiam crianças, na época, caracterizadas de anormais nas áreas do caráter, psíquica, física e moral. O intuito maior era a unificação institucional, para a reclusão de crianças consideradas inúteis, anormais ou que apresentassem perigo à sociedade. Contudo, seu plano não logrou êxito, pois as instituições existentes estavam ligadas a Ministérios diferentes, e, portanto, atendiam interesses políticos distintos, impossibilitando assim a sua junção.

A incessante busca pela normalização do sujeito se voltava tanto para que se viabilizasse o controle do Estado sobre a vida do indivíduo, como por uma questão econômica, pois havia uma preocupação com relação aos gastos que se tinha com os desvalidos, como nos mostra Müller (2005):

Este esquadrinhamento era parte integrante do processo de normalização. Percebe-se a compreensão do internamento como processo necessário para que a criança se curasse, regenerasse e tornasse um sujeito produtivo, podendo então, devolver ao Estado e à sociedade o que com ela fora gasto. [...] (MÜLLER, 2005, p. 432)

Aqueles para os quais as técnicas psiquiátricas não surtiam efeito eram encaminhados para um processo educativo voltado apenas para a aquisição de conteúdos funcionais. Esses conteúdos também chamados de atividades da vida diária, quando se pretendia torná-los o mais próximo do padrão socialmente estabelecido. "Ao atingirem a maioridade realizava-se a permuta da ala infantil para a dos adultos, onde eles eram entregues ao esquecimento até mesmo institucional". (MÜLLER, 2005, p.9)

Segundo Marques et al, (2009), no contexto institucional, o indivíduo perde suas características individuais e recebe o estigma do segmento ao qual pertence. Ou seja, 
envoltos pelas paredes da instituição, a pessoa abstrai-se de suas particularidades enquanto sujeito desejante, possuidor de capacidades, e, ganha um estereótipo próprio do grupo ao qual pertence. Assim, vê-se um aluno com deficiência intelectual, por exemplo, como igual a todos os outros, desprovido de suas características individuais.

Ao refletirmos sobre os benefícios da institucionalização da pessoa com deficiência, percebemos que suas vantagens são voltadas para a sociedade, que sob o olhar beneficente redime-se do peso da culpa pela segregação histórica. Do ponto de vista dos institucionalizados, tem-se um prejuízo pela privação cultural, a qual é submetida, uma vez que, as aprendizagens e aquisições das funções superiores são mediadas a partir dos processos coletivos.

De acordo com Marques et al, (2009), Vygotsky (2000) tece uma crítica acerca dos profissionais especialistas que se focam nos exames, que apontam tão somente para as limitações do indivíduo. A partir da realização de testes padronizados, esses educandos são categorizados e encaminhados às escolas e demais serviços especializados, onde muitos permanecem isolados ao longo de suas vidas.

A visão de Foucault (1999) sobre essa perspectiva médica "patologizante" coaduna com o parecer de Vygotsky, quanto ele critica os exames clínicos, que classificam a pessoa, declarando que,

O exame assumiu um importante papel no processo de isolamento dessas pessoas em diferentes instituições. Foucault, (1999, p. 107) destaca que o exame é a vigilância permanente, classificatória, que permite distribuir os indivíduos, julgá-los, medi-los, localizá-los, e, por conseguinte, utilizá-los ao máximo. (MARQUES, et al, 2009, p. 83)

Foucault (1999) aponta os exames diagnósticos como um aparelho classificatório, que são utilizados para categorizar as pessoas, justificando seu afastamento social bem como o enclausuramento em hospitais, escolas e demais instituições especializadas, aos quais se confere o cuidado às pessoas com deficiência e demais indivíduos, que possuam características fora dos padrões socialmente estabelecidos como normais. 
O exame assumiu um importante papel no processo de isolamento dessas pessoas em diferentes instituições. Foucault $(1999,107)$ destaca que o exame é a vigilância permanente, classificatória, que permite distribuir os indivíduos, julgá-los, medi-los, localizá-los, e, por conseguinte, utilizá-los ao máximo. (MARQUES, et al, 2009, p. 85)

De acordo com Mendes (2006), em resposta aos rígidos processos de institucionalização, a que eram submetidas às pessoas com deficiência, entre outros sujeitos desviantes, surgiu nos países escandinavos um princípio que ficou conhecido como normalização. Tal ideologia consistia em assegurar àqueles com algum tipo de deficiência a irrestrita oportunidade de participar da vida social da comunidade ao qual estava inserido, compartilhando e vivenciando trocas de experiências com seus pares de faixa etária, experienciando aquilo que se considerava normal dentro da cultura local.

\subsection{Mudança e a (re)significação dos motivos}

Segundo Duarte (2004), o elemento que se interpõe entre a ação do sujeito e o motivo de sua ação, de modo a produzir sentido para si, são essencialmente às relações tecidas entre o sujeito, os outros e tudo mais que integra o contexto histórico e social ao qual está inserido, pois, "somente como parte desse conjunto é que o indivíduo adquire um sentido racional". (DUARTE, 2004, p. 53-54)

Na mesma perspectiva, Leontiev (1959) revela que as razões que motivam o indivíduo a realizar a ação se constituem a essência do sentido, no momento em que se põe em relação diretamente com o fim último desta ação. Ou seja, a força motriz que conduz o sujeito á realização da ação aliada à direção ao qual se norteia a prática (aonde se quer chegar), "dá a luz" ao sentido que emana do sujeito e orienta suas práticas de modo não alienado.

Leontiev (1959) nos esclarece acerca da consciência alienada, apontando-nos que a sociedade capitalista altera a relação harmônica entre os motivos que geram os sentidos e os significados, que produzem a ação humana. Ou seja, muitas vezes somos levados a reproduzir determinados conceitos e práticas, que são discrepantes 
daqueles que acreditamos, e, que nos satisfazem, pelo fato de estarmos inseridos em uma lógica contraditória. Nesse caso, o conteúdo objetivo da atividade não concorda com seu conteúdo subjetivo, uma vez que,

A "alienação" da vida do homem tem por conseqüência a discordância entre o resultado objetivo da atividade humana e o seu motivo. Dito por outras palavras, o conteúdo da atividade não concorda agora com o seu conteúdo objetivo, isto é, com aquilo que ela é para o próprio homem. Isto confere traços psicológicos particulares à consciência. (LEONTIEV, 1959, p. 130)

$\mathrm{Na}$ constituição dos sentidos está o motivo que impulsiona o indivíduo à realização de suas atividades e a relação com o fim último desta mesma atividade. De acordo com Leontiev (1978, P. 97): "o sentido pessoal traduz a relação do motivo com o fim". Desse modo, se pretendemos compreender a mudança humana em todos os seus níveis, faz-se necessário esquadrinhar as motivações que produzem o sentido que através de seus significados desencadeiam novas práticas. "[...] Portanto, para investigarmos o sentido pessoal que uma atividade ou conhecimento tenha para um sujeito, é fundamental analisar seu motivo". (LEONTIEV, 1978, p.230)

O homem assume a condição humana, por se constituir dentro de um contexto histórico e social. A partir da visão vygotskiana, não se separa a palavra de sua dimensão contextual, pois não se pode prescindir da palavra fora das condições de produção e da interpretação do que é dito. As condições de produção se referem exatamente ao contexto sócio-histórico, ao qual se menciona a palavra e a interpretação do que é dito. Remete-se ao sentido individual, que se atribui ao signo ou ao discurso, que, por sua vez, emerge das relações e experiências dentro desse mesmo contexto.

Para compreender a construção do sentido faz-se necessário entender a construção do significado, bem como diferenciá-los. De acordo com Vygotski (1993), o significado vem a ser a unidade da palavra em seu aspecto generalizante, ou seja, a convenção ou a construção generalizada se constitui o fundamento do significado. 
Segundo Leontiev (1959), a significação vem a ser generalização de uma dada realidade que se corporifica na palavra, no verbo. Desse modo, a significação se manifesta em toda a produção humana culturalmente organizada e se amalgama na realidade histórica e social, a exemplo disso: a língua, a ciência, a música, entre outros, são construções historicamente construídas e integram o código de significações existentes, como nos esclarece abaixo:

A significação é a generalização da realidade que é cristalizada e fixada num vetor sensível, ordinariamente a palavra ou a locução. É a forma ideal, espiritual da cristalização da experiência e da prática sociais da humanidade. A sua esfera das representações de uma sociedade, a sua ciência, a sua língua existem enquanto sistemas enquanto sistemas de significação correspondente. A significação, pertence, portanto, antes demais ao mundo dos fenômenos objetivamente históricos. E desse fato que devemos partir. (LEONTIEV, 1959, p.100)

Psicologicamente, os significados são absorvidos pelo indivíduo no contato com o meio social ao qual está inserido. $\mathrm{Na}$ medida em que este absorve os diferentes signos, ele também os constrói e os reconstrói, pois integra um determinado contexto histórico. De acordo com Leontiev (1959), esse reflexo generalizado pela sociedade é internalizado pelo sujeito e cristalizado por intermédio de conceitos extraídos de saberes e fazeres estabelecidos, como os padrões comportamentais, as regras de conduta, etc.

O processo de significação ocorre para além da vontade individual, ou da relação que se tenha com tais signos. Ao nascer, o indivíduo encontra uma série de significações pré-existentes, das quais precisa se apropriar ou se adaptar. Esses sistemas são construídos historicamente e servem como uma espécie de instrumento para sua atuação social.

O modo como ocorre o processo de assimilação dessas significações, ou seja, a forma como cada indivíduo se relaciona com esse sistema de significados delineia o sentido pessoal do sujeito. Para Leontiev (1959) aí se define o fenômeno eminentemente psicológico, pois, 
[...] o fato propriamente psicológico, o fato da minha vida, é que eu me aproprie ou não, que assimile ou não uma dada significação, em que grau eu assimilo e também o que ela se torna pra mim, pra minha personalidade; este último elemento depende do sentido subjetivo e pessoal que esta significação tenha pra mim. (LEONTIEV, 1959, p. 102)]

A elaboração do sentido organizada por VYGOTSKY (1993) estabelece um corte entre a linguagem endógena e exógena. Ou seja, é toda a carga de representatividade que a palavra traduz para o indivíduo, mediante suas experiências individuais em um cenário social e histórico, que o influencia, ao mesmo tempo, em que é influenciado pelo sujeito.

Assim, ao buscarmos compreender a consciência humana por meio da introspecção, parece haver certa fusão entre significado e sentido. Entretanto, devemos entender que, embora esses dois processos estejam intimamente ligados, podemos distingui-los, inicialmente, pela ordem se sua precedência, pois, de acordo com Leontiev (1959:104), "é o sentido que se exprime nas significações (como o motivo nos fins) e não a significação no sentido".

É dentro de um cenário socio-histórico que se criam os significados. Da relação do sujeito com esses significados se constroem os sentidos pessoais. Do mesmo modo, existe uma relação coletiva de um determinado grupo com os significados historicamente construídos, o que torna possível a elaboração de um sentido coletivo. Ou seja, existe um modo grupal de conceber os significados estabelecidos.

Esse sentido coletivo é construído a partir de um processo dialético, de conflitos, de construções e desconstruções, que se dá em nível coletivo, assim como um tecido que vai se tecendo, de maneira que os fios entrelaçados vão criando forma até darem origem a um todo, onde não se vê apenas uma junção de fios, mas um tecido, com cor, textura, largura e cumprimento próprios.

2.3 As instituições especializadas e suas possíveis contribuições para o processo de inclusão escolar

Nesse novo contexto educacional inclusivo, caberá a instituição especializada auxiliar, por meio da identificação, da avaliação das necessidades educacionais 
especiais dos alunos, da interlocução e do planejamento voltada para as respostas educativas no contexto inclusivo.

As instituições especializadas também apoiarão o sistema educacional inclusivo na orientação e formação dos agentes intervenientes no processo de formação do educando público alvo da educação especial.

Considerando o grave fato de que a maioria das escolas comuns dizem estar "despreparadas" para receber alunos com deficiência -já que grande parte dos alunos nunca freqüentou a escola de ensino regular -, a instituição especializada deve oferecer apoio e conhecimentos/esclarecimentos aos professores das escolas comuns em que essas crianças estão estudando. (FÁVERO, PANTOJA, MANTOAN, 2007, p.32)

Do mesmo modo, a instituição especializada dará assistência à escola comum, na confecção de materiais adequados aos diferentes tipos de necessidades dos alunos, bem como na assessoria para a aquisição destes.

Para crianças de 0 a 2 anos, as instituições especializadas podem ofertar 0 Atendimento Educacional Especializado por meio da intervenção precoce ${ }^{1}$, quando necessário, resguardando sempre o direito desses alunos frequentarem os espaços de ensino comum destinados a esse público, sendo estes creches e centros de educação infantil, que compreendem a faixa etária de 0 aos 5 anos de idade.

Nos casos em que o aluno público alvo da educação especial seja maior de 14 anos e optar por uma escola regular profissionalizante ou pela Educação de Jovens e Adultos - EJA, as instituições especializadas também podem oferecer o atendimento Educacional Especializado, caso seja necessário. (FÁVERO; PANTOJA; MANTOAN, 2007).

A Declaração de Salamanca (UNESCO, 1994) orienta as "escolas especiais" que intensifiquem a parceria com as instituições oficiais, corroborando em seus

\footnotetext{
1 Por intervenção precoce entende-se o oferecimento à criança de recursos ambientais apropriados (físicos, tecnológicos, materiais e humanos) a proporcionar-lhe interações ativas que ensejam mudanças significativas em seu processo evolutivo. (BRASIL, 1995, p.14)
} 
planejamentos, implementações e avaliações, para que juntas garantam respostas inclusivas e exitosas, por parte dos alunos, que são público-alvo da educação especial.

As escolas comuns, com a atual incumbência de incluir a todos, indistintamente, necessitarão de apoio, no tocante a sua organização para aquisição de respostas educativas para os alunos público alvo da educação especial. Neste novo modelo, esses alunos receberão o atendimento educacional especializado, sempre que necessário, para complementar ou suplementar seus estudos. Enquanto as escolas comuns poderão ser apoiadas pelas instituições especializadas, uma vez que, o papel da escolarização cabe única e exclusivamente a ela.

As instituições especializadas, públicas, privadas e privadas sem fins lucrativos, mesmo que já ofertem o Atendimento Educacional Especializado, devem orientar as famílias e encaminhar todos os seus alunos a realizarem a matrícula, sobretudo aqueles com idades de 06 (seis) aos 14 (quatorze) anos, nas escolas da rede regular de ensino, como garantia do cumprimento da Lei $n^{\circ} 9.394$ em seu artigo 32, que prega a sua gratuidade e obrigatoriedade nessa faixa etária.

As instituições especializadas no atendimento de alunos público-alvo da educação especial devem oferecer os conhecimentos, que não são próprios do currículo da chamada base nacional comum. De igual modo, devem estar atentas para que as escolas comuns cumpram o que lhes é de competência: a escolarização de todos, independente de suas diferenças ou limitações.

O importante papel da instituição especializada é o de oferecer aos alunos com deficiência conhecimentos que não são próprios dos currículos da base nacional comum e, como defensores das pessoas com deficiência, cuidar para que as escolas comuns cumpram seu papel. Caso sejam encontradas resistências das escolas comuns da rede regular em aceitar as matrículas, ou manter as já existentes, mesmo como apoio das instituições especializadas, os dirigentes dessas devem orientar e acompanhar os pais para denunciarem o fato nos órgãos do Ministério Público local. (FÁVERO; PANTOJA; MANTOAN, 2007, p. 33)

Ainda não é consenso à aceitação e apropriação do processo de inclusão, por parte das escolas especializadas. Inúmeros movimentos de resistência têm surgido em 
combate à nova postura educacional. Dentre as alegativas, pelas quais se luta pela permanência das antigas escolas especiais como substitutiva da escola comum, está a de que alguns alunos requerem apoios permanentes e generalizados, e o sistema regular é despreparado para lidar com esses casos. Outra justificativa se ancora na própria importância histórica que tem a escola especial na educação de alunos com deficiência. Além do direito de escolha, que dever ser preservado ao educando e a família que decidirão qual o melhor lugar para construírem sua escolarização. Como pode ser visto no documento em que se posiciona a Federação Nacional das APAE's sobre tal assunto:

Sob tais enfoques, a Federação Nacional das APAE's defende a continuidade e a manutenção das escolas especiais, como espaços de direito e, portanto, tão inclusiva quanto as escolas comuns concernente ao direito à educação em escolas especiais dos educandos que, em função das suas condições específicas, não for possível a sua integração nas classes comuns de ensino

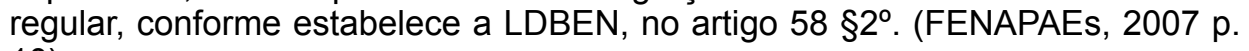
10)

Alguns grupos defensores da "escola especial" não aceitam o seu redimensionamento, por julgarem que, neste contexto, se limitaria a uma educação não formal, minimizando assim suas possibilidades, em relação à escolarização de seu público, que, em alguns casos, dependeria, exclusivamente, de seus conhecimentos para sua inclusão social.

Escolas de línguas, de música, de arte, de culinária e outras não são escolas formais como requer o sistema educacional escolar. São pertencentes ao sistema não formal de educação. Assim, reduzir a compreensão de escola especial à oferta apenas de educação não formal é retirar a oportunidade única de alguns alunos se apropriarem do conhecimento necessário e imprescindível ao convívio social. (FENAPAEs, 2007 p.9)

Para Carvalho (2004), a simples inserção de estudantes com deficiência em salas comuns, não se traduz em modelo de inclusão, pois, nesses casos, o educando não passa de mero coadjuvante em seu próprio processo de busca, sem nenhuma autonomia, nem condições adequadas à construção do conhecimento. 
No entanto, inserir esses aprendizes nas escolas comuns, distribuindo-os pelas turmas do ensino regular, como "figurantes", além de injusto, não corresponde ao que se propõe no paradigma da educação inclusiva e, de igual modo, não vamos contribuir para o seu desenvolvimento integral. (CARVALHO, 2004, p. 110).

Como contraponto a essa postura segregadora de algumas instituições especializadas, ressaltamos a impossibilidade de incluir sem trazer para dentro àqueles que estão do lado de fora. Por mais que estudemos sobre pessoas com deficiência, não há como compreender suas verdadeiras necessidades e aspirações se não estivermos em contato com elas. É no contato com as diferenças, contradições e conflitos, que se formam as bases dialéticas da educação emancipatória, que contempla o homem em suas mais diferentes formas de ser.

Sustentar que primeiro é preciso preparar a escola e os professores para, somente depois, garantir a presença dos alunos é, no mínimo, não compreender a inclusão segundo as leis da dialética, como relação contraditória que ao mesmo tempo em que avança, encarando novos elementos sociais, também conserva as bases do velho já cristalizado e disseminado no conjunto da sociedade. Por isso, não se faz inclusão sem a presença dos excluídos e não se educa pessoa com deficiência sem a sua presença; educação é relação ou não é educação. (ROSSETTO, 2006, p. 86)

Desse modo, é preciso que o aluno da educação especial tenha as condições necessárias para a livre participação em todas as atividades inerentes à vida escolar, das mais simples às mais complexas, respeitando sempre seus ritmos e individualidades.

Em todo o Brasil, uma pequena quantidade de instituições especializadas passou a assumir uma nova postura em relação à escolarização dos alunos com deficiência; o atendimento educacional especializado em uma perspectiva complementar a escola comum. A partir dessa concepção, tais instituições iniciaram um processo de transformação, visando atender as novas demandas oriundas da inclusão de seus alunos. 


\section{PERCURSO METODOLÓGICO}

Esta é uma pesquisa de natureza qualitativa, cujo delineamento metodológico escolhido, estudo de caso, objetivou investigar as mudanças ocorridas na APAE/ Maranguape na nova conjuntura que lhe é posta, sendo esta, a inclusão escolar. Dentro dessa realidade, esse tipo de instituição, que protagonizou, durante muito tempo, a assistência às pessoas com deficiência, vem assumindo um novo papel. Visto que as políticas públicas vigentes traçam um novo caminho para este segmento, que Ihes possibilita o acesso às escolas comuns, preservando-lhes o direito de serem atendidos em suas especificidades, por meio do atendimento educacional especializado.

A escolha por pesquisar a APAE/Maranguape, deu-se devido aos seus aspectos peculiares dentro do cenário que hora cerca as instituições especializadas no país. A instituição escolhida se destaca pela flexibilidade, aceitação e atitude mediante o processo de transformação, que ora se submete. Assim, as particularidades existentes nesta APAE, ratificam nossa escolha metodológica, pois vem ao encontro do que prega Mazzotti (2006), quando fala da necessidade de esclarecer os motivos pelos quais levaram o autor a optar por esse e não aquele universo de pesquisa.

[...] Freqüentemente, o autor apenas aplica um questionário ou faz entrevistas em uma escola, sem explicitar por que aquela escola e não outra, deixando a impressão de que poderia ser qualquer uma. Ou seja, a escola ou a turma escolhida não é um "caso", não apresenta qualquer interesse em si, é apenas um local disponível para a coleta de dados. Em conseqüência, a interpretação desses dados é superficial, sem recurso ao contexto e à história. (MAZZOTTI, 2006, p.26)

Apesar da abertura e maleabilidade da instituição pesquisada, faz-se necessária a investigação e a reflexão sobre a compreensão das mudanças dentro desse novo paradigma, que a ela se antepõem. Desse modo, optamos pelo estudo de caso por atender as expectativas existentes, quanto à obtenção das respostas referentes às mudanças, diante do novo papel das instituições especializadas no contexto da inclusão. Que mudanças estão ocorrendo na instituição devido a essa nova proposta? 
Como vem acontecendo o processo de ressignificação e redimensionamento da instituição dentro do sistema educacional inclusivo? Por que razão a APAE/ Maranguape assumiu as mudanças relativas à inclusão escolar? São questões que poderão ser respondidas através dessa estratégia metodológica, como afirma YIN (2001):

Em geral, os estudos de caso representam a estratégia preferida quando: se colocam questões do tipo "como" e "por que"; o pesquisador tem pouco controle sobre os acontecimentos; o foco se encontra em fenômenos contemporâneos inseridos em algum contexto da vida real. (YIN. 2001, p. 110)

Como participantes da pesquisa, foram escolhidos dois professores do AEE, a coordenadora do Centro de Atendimento Especializado às Pessoas com Deficiência (CAEPD), dois professores do projeto Temperando e Transformando, a professora do projeto Telecentro e a consultora da APAE/Maranguape.

Para o desenvolvimento desta pesquisa seguiram-se algumas etapas indispensáveis à sua viabilização. Como primeira etapa, tivemos a apresentação do projeto na APAE/ Maranguape, buscando o envolvimento do grupo dos profissionais participantes, através da negociação do foco e das estratégias de pesquisa. Em seguida, foram utilizados dois procedimentos metodológicos sendo estes: a entrevista semi-estruturada e a análise documental.

Foram aplicadas duas entrevistas para cada participante, sendo que, uma conteve questões inerentes à sua percepção e a repercussão da mudança no âmbito pessoal, e, a outra sobre as implicações percebidas na esfera institucional. É válido mencionar que a entrevista foi desenvolvida com base em um roteiro com aproximadamente oito questões, variando segundo o sujeito entrevistado.

Ao todo realizamos quatorze entrevistas para sete participantes, sendo estes: a coordenadora (entrevistas 1 e 2) do CAEPD, dois professores do AEE (entrevistas 1 e 2), uma professora e uma terapeuta ocupacional do Projeto Temperando e Transformando (entrevistas 1 e 2), uma professor do projeto Telecentro (entrevistas 1 e 2) e a consultara da APAE (entrevista 1 e 2) totalizando 14 entrevistas. 
Optamos por tais profissionais, por serem representativos do processo de mudança. A oferta do AEE, por exemplo, trouxe uma série de modificações de ordem pedagógica, administrativa e de estrutura física, entre outras. Foram estabelecidas novas relações com as famílias, com os professores de sala de aula comum e com o próprio aluno. Isto porque a oferta da instituição deixa de ser substitutiva à escola comum para ser complementar/suplementar, alterando assim a dinâmica e o funcionamento da instituição como um todo.

Prosseguimos com a coleta de dados através da análise dos documentos, que segundo Yin (2001) este recurso se adequa a todos os tipos de estudos de caso, menos para a investigação de sociedades, que ainda não haviam se apropriado das técnicas de leitura e escrita. Destaca este autor que, as informações extraídas destas fontes devem-se ater exclusivamente à coleta de dados.

É necessário ressaltar que, ao pesquisarmos os documentos em um dado campo de pesquisa, devemos atentar para o fato de tais instrumentos terem sido elaborados em um contexto que não é neutro. Ou seja, existiu uma tendenciosidade em favor de grupos específicos, e, que, portanto, em muitos casos, se chocam com os anseios do estudo de caso, ora desenvolvido. Desse modo, o pesquisador pode confrontar tais documentos com outras fontes, o que enriquecerá o trabalho e dará mais clareza no instante da análise dos dados, como esclarece Yin (2001), ao afirmar que,

[...] de fato, é importante, ao se revisar os documentos compreender-se que eles que eles foram escritos com algum objetivo específico e para algum público específico, diferentes daqueles do estudo de caso que está sendo realizado. Nesse sentido o pesquisador é um observador vicário, e as provas documentais refletem uma certa comunicação entre outras partes que estão tentando alcançar outros objetivos. (YIN. 2001, p. 110)

Assim, elegemos para análise o Projeto Político Pedagógico (PPP), por se tratar do principal documento norteador das concepções e práticas da instituição. Nele estão contidos o diagnóstico situacional do contexto ao qual se insere a instituição, bem com 
as concepções políticas, filosóficas e pedagógicas que orientarão a sua prática, contendo assim, a proposta pedagógica que fundamenta sua oferta educacional.

\section{DISCUSSÃO E RESULTADOS}

Como resultante de um processo socio-histórico, movida por uma constante relação com os indivíduos, que atuam numa dada ordem conjuntural, seria simplório dizer que, a mudança é apenas o resultado de uma soma de partes que, individualmente, se modificam e se juntam para a formação de um todo. Ao contrário, a mudança se produz em um espaço, em um determinado tempo, em um contexto sociocultural, que, por sua vez, é composto por indivíduos que transformam e são transformados, que atuam sobre uma realidade coletiva, ao mesmo tempo, em que são modificados por ela.

Mediante a esta lógica, a pesquisa nos leva a compreender que as mudanças ocorridas na APAE/Maranguape possuem uma força motriz instalada nas subjetividades dos sujeitos, que compõem a instituição. Essas motivações, numa perspectiva dialógica, deram origem aos objetivos do grupo, que se fortaleceram ao longo das discussões coletivas no interior do organismo institucional, tornando possível a luta da instituição frente as resistências, que se estabeleceram no ambiente externo. Resistência que, pode ser encontrada na fala expressa pela atual consultora da APAE no diálogo com outras instituições especializadas:

Primeiro a instituição buscar sua auto-afirmação. Esse é um ponto dificílimo de auto-afirmação enquanto papel social e político. Até ela desmistificar isso porque ela é pequena diante de uma imensidão de outras instituições que ainda querem sustentar esse conceito do passado. Então não é fácil, pois, em todos os lugares ela enfrenta isso: ah, vocês não querem ser escola? Então, esse é um preconceito, uma resistência ainda intensa. Ex-presidente da APAE e atual consultora.

Desse modo, para compreender os aspectos motivacionais que propiciaram a mudança dialogamos com aqueles que compõem a instituição, na tentativa de acessar o que seria a causa primeira da mudança: as concepções. De modo que, os processos 
posteriores: mudança nas práticas pedagógicas e mudança nas relações são conteúdos decorrentes desse movimento anterior, que, por vezes, se instalam no reino do oculto, mas se expressam por meio de práticas, gestos, comportamentos, atitudes, posicionamentos e abstenções. Embora as motivações se expressem de várias maneiras, buscamos uma unidade na construção da motivação coletiva, por meio das trocas sistemáticas dos saberes existentes, com vistas ao fortalecimento do ideário coletivo. Como estratégia foram criados espaços para estudos e discussões como nos mostra a coordenadora do CAEPD ao revelar que o primeiro passo foi,

[...] a questão da formação continuada dos profissionais, porque enquanto escola, nós estávamos com um grupo de profissionais que mesmo que passassem por diversos cursos, eles ainda não estavam habilitados no sentido da parte específica para atender. Do ponto de vista legal, para o centro existir de fato nós precisávamos credenciá-lo e ter os profissionais habilitados. Isso na parte pedagógica, no que se refere à formação. Coordenadora do CAEPD.

$\mathrm{Na}$ busca por viabilizar o processo inicial num plano conceitual é imprescindível que se construam aportes teóricos, que sustentem os objetivos aos quais se persegue, sob pena de se perder o rumo durante a caminhada. A gestação da ideia se dá por meio das discussões, negociações, dos pontos e contrapontos, haja vista estarem em cena um conjunto heterogêneo de valores individuais, embora movidos por um objetivo comum, que é a inclusão escolar dos alunos público-alvo da educação especial.

Vygotsky (2001) nos revela o que o conteúdo manifesto por trás do discurso externo, é repleto de desejos, necessidades e motivações, que buscam atender aos nossos interesses e emoções. É bem verdade que tal conteúdo denominado de discurso interno, sofre a influência do contexto, ao qual se insere o locutor, e, é resultante de um processo relacional, estabelecido numa realidade que é história e social. Entretanto, é da interação desses discursos endógenos, que se configura um sentido coletivo, que dá sustentação ao discurso do grupo e se traduz a partir das novas práticas. 
Desse modo, entendemos que o Projeto Político Pedagógico, por ser um documento coletivo, expressa os significados e práticas, que norteiam a direção a qual a instituição pretende seguir. $\mathrm{Na}$ construção dessas concepções, os sentidos pessoais e coletivos atribuídos a tal documento trazem em seu cerne os motivos, que os une e os mobiliza frente aos desafios para a elaboração da sociedade almejada pelo grupo. No trecho abaixo extraído do Projeto Político da APAE/Maranguape, visualizamos as concepções, que fundamentam suas novas práticas. Nele se encontram expressos a forma como compreendem o processo de aprendizagem de todas as pessoas, bem como revela o significado atribuído à escolarização das pessoas com deficiência, na tentativa de superar a segregação a qual foram submetidas.

Respaldado no princípio da inclusão, o CAEPD busca a superação do caráter substitutivo da Educação Especial ao ensino comum, atuando de forma complementar, consoante às necessidades específicas dos alunos, levando-os a desenvolver os aspectos cognitivos, sociais, psicomotores, afetivos e culturais no processo de aprendizagem. (Trecho da fundamentação pedagógica do PPP - APAE/Maranguape, 2013)

Na ótica de Leontiev (1978), uma atividade é composta pelo conjunto de ações desenvolvidas pelos indivíduos de um grupo em torno de uma mesma finalidade ou objetivo. Cada ação individual é movida pelo significado coletivo construído para um fim objetivo e específico. Assim, o sentido que cada sujeito atribui a sua prática deverá estar em sintonia com a finalidade objetiva ao qual se desdobra sua ação.

Sendo o motivo o núcleo central do sentido que atribuímos à atividade produtiva, dois foram apontados nas entrevistas como causas promotoras da mudança, a saber: a defesa dos direitos da pessoa com deficiência e a aprendizagem e o desenvolvimento do aluno. Embora exista um aparato legal, que garante a inclusão ampla e irrestrita dos alunos com deficiência nas escolas comuns do ensino regular, vemos que, na prática muitos desses direitos são burlados, em nome de uma "falta de preparo", por parte de diversas unidades escolares. Assim, observamos na fala da professora 01 do AEE que se faz necessário um acompanhamento da execução das leis, para que se garanta o processo de inclusão de fato e de direito. 
[...] a APAE é uma instituição cujo objetivo é a defesa dos direitos das pessoas com deficiência, e, devido à mudança das leis, diretamente relacionada ao MEC, a APAE sentiu a necessidade de acompanhar o processo de inclusão nas escolas regulares. Professora 01 - AEE.

Entendendo a Educação como um direito de todas as pessoas, os alunos com deficiência, historicamente foram postos à margem desse direito. Desse modo, a professora 01 do AEE relata que a principal motivação da mudança é a defesa dos direitos da pessoa com deficiência. Uma vez que a forma como esse direito é validado requer atenção para que o fim último de sua inclusão seja a sua aprendizagem e a formação de cidadãos autônomos e socialmente ativos. Dentre as medidas necessárias à viabilização desse processo, o acompanhamento às famílias é apontado como fundamental, como vemos abaixo:

[...] Eu acho que o objetivo fundamental da instituição é consolidar o processo de inclusão. Acompanhar as famílias, dar apoio às famílias, continuar em defesa dos direitos das pessoas com deficiência. Proporcionar estudos, realizar campanhas na comunidade, mas, fundamentalmente continua sendo a defesa dos direitos das pessoas com deficiência do município de Maranguape. Professora 01 - AEE,

Um novo significado para a pessoa com deficiência se faz necessário. Em primeiro lugar que seja tratada como cidadã de direito e não como aquele que de favores necessita. Que seja visto como um SER, dotado de todas as dimensões do humano; alguém que pensa, que sente, que ama, que se relaciona. Um ser humano ativo do ponto de vista social, político e econômico. A despeito disso nos fala a superintendente da APAE/Maranguape quando descreve os motivos da mudança:

Primeiro eu acho que foi a dignidade e o direito da pessoa com deficiência que fez a APAE mudar. A questão da pessoa com deficiência foi o primeiro plano que levou a APAE mudar. Da ressignificação desse indivíduo enquanto sujeito diante de uma sociedade. E fazer com que a sociedade respeite e não dava pra ter duas falas. Dentro da instituição ter uma fala e na sociedade ter outra. Eu acho que foi esse grande passo; a ressignificação da vida. E pensar o sujeito enquanto ator importante dentro de uma sociedade produtiva, econômica, política... Esse foi o grande propósito que a instituição teve. Expresidente da APAE atual superintendente. 
A participação de todos os indivíduos na gestão e nas decisões que afetam a sociedade é a primeira arma de empoderamento, que garante a pessoa com deficiência o exercício de sua cidadania. Pensar em uma política voltada para a promoção da inclusão de qualquer segmento social segregado é pensar em um modelo participativo, em que os maiores interessados tenham vez e voz nas tomadas de decisões. Caso contrário, estaremos diante de sofismas, de falácias, com lacunas absurdas entre o dizer e o fazer as práticas inclusivas. Como nos mostra a fala da atual superintendente da APAE/Maranguape, a Educação é um dos principais instrumentos de empoderamento, é, em si, um mecanismo que possibilita ao sujeito se apropriar do saber historicamente construído para uma atuação mais prática na sociedade ao qual está inserido.

\begin{abstract}
Hoje ela busca oferecer a esses atores importantes ações que possam contribuir com a vida, fazendo com que eles possam crescer. Que possa ajudar hoje na defesa dos seus direitos. Então, eu acho que a instituição tem muito mais hoje um papel de defesa de direitos, na garantia dos direitos e na luta e promovendo isso junto com as famílias e com a pessoa com deficiência do que fazer um papel do estado. Ex-presidente da APAE.
\end{abstract}

Não se objetiva, de nenhum modo, negar o componente individual no processo de construção do sentido, mas, considerar as relações existentes dentro de um contexto histórico, que repercutem no sujeito influenciando até mesmo a sua forma pessoal de se relacionar com as significações socialmente construídas. É possível perceber nas considerações da atual superintendente da APAE/Maranguape, o sentido que atribui ao processo de mudança, por meio de uma contextualização histórica que desencadeou o paradigma da inclusão, atualmente defendido pela instituição.

Sinceramente, eu tenho imenso prazer em dizer que faço parte dessa construção. Tenho muito cuidado com o que eu falo, com o que eu leio, com o que eu pratico. Apesar de ter nascido numa história de segregação, tem que ter cuidado muito com esse processo. Mas, sinto um prazer enorme e um orgulho enorme de fazer parte dessa construção. Superintendente da APAE/ Maranguape.

Indagada sobre a forma como a mudança foi compreendida, a professora 02 do AEE destaca como a nova concepção voltada para atender a proposta inclusiva pode 
refletir em sua prática pedagógica, levando-a a perseguir um novo objetivo a partir de um conteúdo anteriormente trabalhado.

\begin{abstract}
Não só pra mim, mas, pra todos os professores, foi a compreensão de como trabalhar cada área. Por exemplo, quando nós trabalhamos com os alunos com deficiência intelectual a construção do nome, alguns imaginavam que nós estávamos ensinando o português, mas, a questão ia além da língua. Nós estávamos trabalhando a identidade, a construção de si mesmo e a construção do mundo a partir deles, de suas identidades individuais dentro de uma realidade social. Professora $2-\mathrm{AEE}$.
\end{abstract}

Assim, uma mudança que se estabelece apenas no nível das práticas não tem sustentação. É necessário que ela crie bases sólidas no ideário coletivo do grupo, possibilitando ao indivíduo, que ele se reconheça dentro do processo de mudança mediante sua ação ativa e transformadora. Caso contrário, as diversas ações serão apenas um subproduto para atender a vontade alheia ou de grupos que estão no poder.

\title{
5 CONSIDERAÇÕES FINAIS
}

Com base nos resultados apontados, percebemos que, o novo sentido que permeia e fundamenta os saberes e práticas da instituição analisada, foi construído através da relação interna de seus profissionais com outras formas de pensar a educação especial. Essas novas formas apontam, principalmente, o direito dos alunos público-alvo da educação especial de se incluírem nas escolas comuns do ensino regular, sendo este o principal recurso de mediação de sua aprendizagem.

Mediante os estudos realizados na instituição, verificamos também que o ambiente heterogêneo e diversificado é a forma mais eficaz de construção de conhecimento. Privar qualquer aluno do privilégio de aprender com as trocas, com as diferenças, é, portanto, podá-lo, reduzi-lo, minimizá-lo em seu potencial de descoberta, privá-lo da capacidade de crescer com os consensos, dissensos e conflitos existentes na coletividade. 
$\mathrm{Na}$ instituição investigada, as discussões e os estudos realizados pelos profissionais com base em autores como Vygotsky, Piaget, Sassak, Mantoan, Figueiredo, Gomes, entre outros, bem como as experiências de outros militantes da causa da inclusão escolar, auxiliaram eles na construção de novas concepções, norteando suas visões frente à responsabilidade de lutar pela inclusão escolar de seus alunos como um direito básico e incondicional.

Para os participantes do estudo, a antiga proposta pedagógica da APAE/ Maranguape que separava seus alunos dos demais, oferecendo-lhes um modelo escolar diferente, em substituição à escola comum, perdeu o sentido. E, em seu lugar, eles se apropriaram de uma nova concepção e prática que privilegia o contato do aluno com seus pares. Dentro desta visão, a instituição vem se empoderando de seu novo papel, que destina a oferta de seus serviços a subsidiar e apoiar seus alunos no desafio de aprender nas escolas comuns do ensino regular, lugar destinado para a escolarização de todos os alunos.

Constatamos que a causa primeira da instituição permanece de forma ainda mais veemente, a saber, a luta pela promoção dos direitos das pessoas com deficiência. Eis a razão pela qual a luta pela inclusão escolar continua sendo uma de suas maiores frentes de luta: a escola comum inclusiva, onde todos os alunos sejam respeitados e valorizados em suas diferenças.

\section{REFERÊNCIAS}

CARVALHO, R. E. Educação Inclusiva com os Pingos nos Is. 2. ed. Porto Alegre: Mediação, 2004.

DUARTE, Newton. Formação do indivíduo, consciência e alienação: o ser humano na psicologia de A. N. Leontiev, Cad. CEDES, Campinas, 2004. Disponível em: <http://www.cedes.unicamp.br>

FÁVERO, A. G.; PANTOJA, L. M. P.; MANTOAN, M. T. E, Atendimento educacional especializado: aspectos legais e orientação pedagógica, São Paulo, MEC/SEESP, 2007. 
FENAPAES, Federação Nacional das APAES, Posicionamento do movimento apaeano em defesa da inclusão escolar de pessoas com deficiência intelectual e múltipla: FENAPAES, 2007.

FOUCAULT, Michel. Microfísica do poder, Rio de Janeiro, Graal, 1999

GUERREIRO, P. (Org.). Instituto Benjamin Constant: 150 anos. Rio de Janeiro: Instituto Benjamin Constant, 2007.

JANNUZZI, G., A luta pela educação do deficiente mental no Brasil, Autores Associados, Campinas, 1992, 2ed.

LEONTIEV, Alexis. 0 desenvolvimento do psiquismo, $1^{\text {a }}$ ed., São Paulo: MORAES LTDA, 1959.

LEONTIEV, A. O desenvolvimento do psiquismo. Lisboa, Livros Horizonte, 1978.

MAGALHÃES, Basílio de., Tratamento e educação das crianças anormais de inteligência: contribuições para o estudo desse complexo problema científico e social, cuja solução urgentemente reclamam, - a bem da infância de agora e das gerações vindouras, - os mais elevados interesses materiais, intelectuais e morais da prática brasileira. Rio de Janeiro, Tip. Do Jornal do Comércio de Rodrigues S. C., 1913.

MARQUES, C. A. \& MARQUES, L. P. et. al, Da exclusão à inclusão: (re)construindo significados à luz dos pensamentos de Vygotsky, Paulo Freire e Michel Foucault, Juiz de Fora, UFJF, 2009.

MAZZOTTI, A. J. A.; GEWANDSZNA J. F. O Método nas ciências naturais e sociais: pesquisa quantitativa e qualitativa. 2. ed. São Paulo: Pioneira, 2006.

MENDES, E. G., A radicalização do debate sobre inclusão escolar no Brasil, In: Revista Brasileira de Educação. v. 11 n. 33, set/dez 2006.

MÜLLER, T. M. P., A primeira escola especial para "creanças anormaes" no Distrito Federal - O Pavilhão Bourneville do Hospício Nacional dos Alienados (1903-1920): uma leitura foucaultiana, Dissertação de Mestrado, UERJ, 1998.

MÜLLER, T. M. P. Os conceitos de criança e de anormal e as práticas decorrentes de atendimento institucional no brasil: uma análise genealógica. Childhood \& Philosophy, Rio de Janeiro, v.1, n.2, jul./dez. 2005. 


\section{EDUCAÇÃO, \\ ARTE'S E INCLUSÃO}

RIBEIRO, L. Papel do médico na solução do problema da delinquência infantil. In Folha Medica, Rio de Janeiro, ano XXIV, 25 de março de 1943.

ROSSETTO, E. et. al, Programa Institucional de Ações Relativas às Pessoas com Necessidades Especiais - PEE. Pessoas com deficiência: aspectos teóricos e práticos, EDUNIOESTE, Cascavel, 2006.

UNESCO, Declaração de Salamanca e Enquadramento da Ação na Área das Necessidades Educativas Especiais. Conferência Mundial sobre Necessidades Educativas Especiais: acesso e qualidade, Salamanca, 1994.

VYGOTSKY, Lev Semionovich. Fundamentos de Defectologia, Madrid, Rógar, 1984.

VYGOTSKY, Lev Semionovich. A construção do pensamento e da linguagem, São Paulo, Martins Fontes, 2000.

YIN, R. K. Estudo de caso: planejamento e métodos. 2 ed. Porto Alegre, Bookman, 2001.

Recebido em 07 de Setembro de 2018

Aprovado em 25 de Março de 2020 